\title{
Selection of cutting and washing fluids as a method of waste minimization
}

\author{
Agnieszka Rymarczyk, Krystyna Mędrzycka, Renata Tomczak-Wandze \\ Gdańsk University of Technology, Chemical Faculty, Narutowicza 11/12, 80-952 Gdańsk, Poland, \\ e-mail: nata@chem.pg.gda.pl
}

\begin{abstract}
The results of the corrosion test for washing and cutting fluids used in the process of gear-shafts production are presented. The test has been performed according to the DIN 51360-2 (Ford-test) and the PN-92/M55789 procedures. Three cutting fluids and three washing fluids were chosen and their solutions in tap water (used in practice in the company) were investigated. On the basis of the obtained results it has been stated that the lower the fluid concentration, the stronger corrosion is developed. The concentrations recommended by the producer in the case of cutting fluids are properly chosen. For washing fluids two regions of concentration have been evaluated. The concentration recommended for rinsing is too low for protection against corrosion, while higher concentrations, for the washing process, are properly chosen, and corrosion did not occur.
\end{abstract}

Keywords: corrosion, cutting fluids.

Presented at VII Conference Wasteless Technologies and Waste Management in Chemical Industry and Agriculture, Międzyzdroje, 12 - 15 June, 2007.

\section{INTRODUCTION}

Corrosion is one of the causes of deterioration of metal products and as a consequence the economic losses can be huge. Depending on the mechanisms of corrosion development, various prevention methods are widely used. In the Pomorian province, in one of the companies producing gear-boxes the problem of corrosion of elements has appeared. Before mounting the gears the components are stored in a stacking yard and it has been found that part of them underwent corrosion, particularly the driving shafts (gear-box shafts) were damaged. Depending on the scale of the corrosion the elements are directed to regeneration or are treated as a discard, which means that they are wastes. In 2004 about $4.11 \%$ of gear boxes were discarded due to corrosion. In 2005 it was about $6.89 \%$.

The main parameter which should be considered is the humidity of the environment at the storage place and also the presence of water during the processing of the metal elements. As water promotes corrosion, it was suspected that washing or cutting processes could enhance the development of corrosion. First, due to the removal of the temporary protecting material (e.g. grease) and secondly, due to the interaction of fluids components with the metal surface $^{1-3}$. Cutting and washing fluids are usually supplemented with corrosion inhibitors and they should effectively protect metal surfaces against corrosion during storing, as well as during exploitation ${ }^{4-5}$. However, in view of the observed extent of corrosion, it has to be checked if the used fluids are properly selected and used. Thus, the aim of the research was to investigate the corrosion protection properties of the fluids, used in the company.

\section{MATERIAL AND METHODS}

The concentrates of three cutting fluids and three washing fluids were chosen and their solutions in tap water (used in practice in the company) were investigated. The concentrations of the tested solutions are given in Table 1. In the table the concentrations recommended by the producer for the preparation of washing and cutting fluids for the use in the process (and such concentrations are applied in the company), have been presented.

Table 1. The concentrations of the technological fluids used in the process of gear-box shafts production and in the experiments

\begin{tabular}{|c|c|c|}
\hline Fluid & $\begin{array}{c}\text { Recomended } \\
\text { concentration } \\
{[\%]} \\
\end{array}$ & $\begin{array}{c}\text { Concentration in } \\
\text { tests } \\
{[\%]}\end{array}$ \\
\hline \multicolumn{3}{|c|}{ Cutting fluids } \\
\hline HoCut 2360 & $3-5$ & $2.21-7.67$ \\
\hline Curtagil M17 & $6-8$ & $3.9-9.2$ \\
\hline B50S & $3-5$ & $1.95-5.55$ \\
\hline \multicolumn{3}{|c|}{ Washing fluids } \\
\hline HoughtoClean 130 & 3 & $1.8-4.32$ \\
\hline \multirow{2}{*}{ HoughtoClean MT } & $\begin{array}{c}3-4 \text { (washing } \\
\text { bath) }\end{array}$ & \multirow{2}{*}{$0.8-4.6$} \\
\hline & $\begin{array}{c}1.1-1.3 \text { (rinsing } \\
\text { bath) }\end{array}$ & \\
\hline \multirow{2}{*}{$\begin{array}{l}\text { Renoclean Brilant } \\
\text { MS } 216\end{array}$} & $\begin{array}{c}3-4 \text { (washing } \\
\text { bath) }\end{array}$ & \multirow{2}{*}{$0.84-4.76$} \\
\hline & $\begin{array}{c}1.1-1.3 \text { (rinsing } \\
\text { bath) }\end{array}$ & \\
\hline
\end{tabular}

\section{CORROSION TEST}

The test was performed according to the DIN 51360-2 procedure (Ford-test), in combination with Polish Standards (PN-92/M-55789) ${ }^{6}$. In the test the cast iron fine chips (swarfs) are placed on a filter paper, which earlier was soaked with the tested liquid. Then, they are kept for 2 hours under the mentioned conditions and afterwards the state of the filter paper is evaluated. The outlines of the corrosion spots are a measure of the extent of corrosion. The numbers of the spots and the surface covered by them are compared with the standard (7-degree scale). In this method the lack of corrosion is identified as 0 and the highest degree of corrosion (very strong corrosion) is identified as 6 (Table 2).

In the current research the cast iron $\mathrm{Nr} 27 / \mathrm{II}$ swarfs were used. 
Table 2. The standard corrosion scale according to PN-92/ M-557896

\begin{tabular}{|l|l|l|}
\hline $\begin{array}{l}\text { Corrosion } \\
\text { degree }\end{array}$ & $\begin{array}{l}\text { Definition/Chara } \\
\text { cterisation }\end{array}$ & $\begin{array}{l}\text { Surface corroded/stained } \\
{[\%]}\end{array}$ \\
\hline 0 & No corrosion & No traces of corrosion \\
\hline 1 & Partial corrosion & $\begin{array}{l}\text { At most 3 spots of corrosion of } \\
\text { the diameters up to } 1 \mathrm{~mm}\end{array}$ \\
\hline 2 & Slight corrosion & $\begin{array}{l}\text { No more than } 1 \% \text { of the } \\
\text { surface, but spots bigger than } \\
\text { for } 1 \text { degree corrosion }\end{array}$ \\
\hline 3 & $\begin{array}{l}\text { Moderate } \\
\text { corrosion }\end{array}$ & $1 \%$ to $5 \%$ of the surface \\
\hline 4 & $\begin{array}{l}\text { Significant } \\
\text { corrosion }\end{array}$ & $5 \%$ to $20 \%$ of the surface \\
\hline 5 & High corrosion & $20 \%$ to $50 \%$ of the surface \\
\hline 6 & $\begin{array}{l}\text { Very high } \\
\text { corrosion }\end{array}$ & Over $50 \%$ \\
\hline
\end{tabular}

\section{RESULTS}

\section{Tap water testing}

In order to evaluate the protective properties of the tested liquids, first the corrosive properties of water had to be investigated. The water used in the company is characterized by its conductivity equal to $650 \mu \mathrm{S}$, the hardness $-13.6^{0} \mathrm{~N}$ and the $\mathrm{pH}-7.2$. The triplicate test shoved very strong corrosive properties of this water degree 6 (Fig. 1).

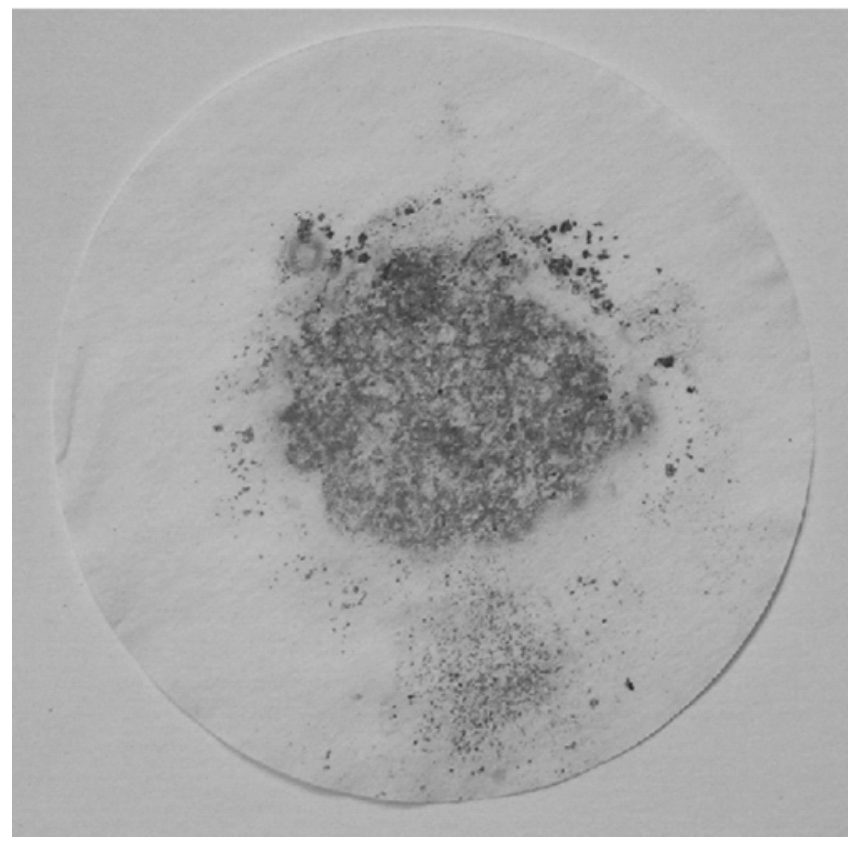

Figure 1. The view of paper disks after the corrosion test for tap water (corrosion degree 6)

\section{Testing of the washing liquids}

Corrosion tests were performed for three washing fluids at their concentrations ranging from below up to above the concentrations recommended by the producer (see, Table 1). The results are presented in Figs $2-5$.

Houghto-Clean MT. This is an alkaline cleaning agent, containing nonionic surfactants and corrosion inhibitors. There are two recommended concentration regions, for washing $3-4 \%$ and for rinsing $1.1-1.3 \%$, (Table 1 ). These regions are presented in Fig. 2 as vertical lines (solid lines for the washing concentration and the dotted lines for the rinsing concentrations). From the data presented in Fig. 2 it results that at the concentration recom- mended for rinsing the observed corrosion can be described as moderate corrosion (corrosion degree 3 ). This means that such concentration is too low to protect the metal surface against corrosion. The view of the filter paper disks after the corrosion test is presented in Fig.3. It is clearly visible that the increase of the fluid concentration above $2 \%$ is necessary, however, even at this concentration the trace corrosion (degree 1) has appeared. The concentration for the washing fluid is properly recommended $(3-4 \%)$ as corrosion has not been observed at such a concentration (Fig.2).

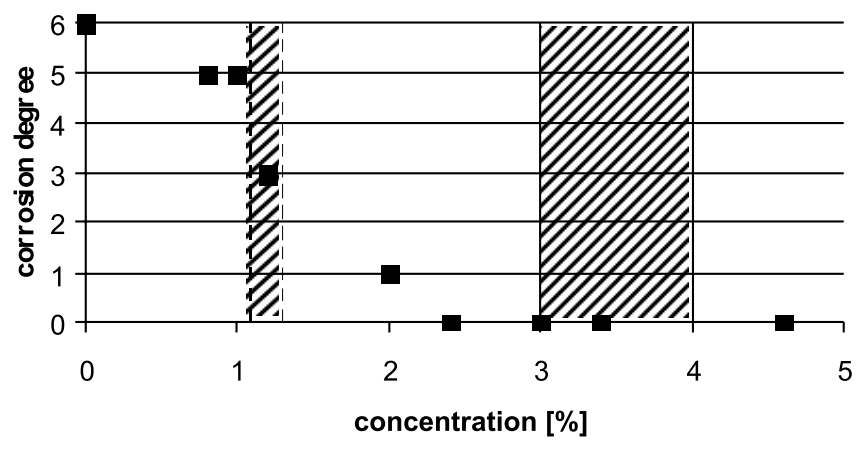

Figure 2. The dependence of the Corrosion Degree on the Houghto-Clean MT concentration in the tested solutions

Renoclean Brilant MS 216. For this agent the recommended concentration is similar to the one for the Houghton-Clean MT. The results obtained from the corrosion tests (Fig.4) are also similar, only the concentration of $2.5 \%$ and higher is satisfactory when anticorrosion protection is considered. The concentrations recommended for rinsing solutions are too low (the corrosion degree was between $3-5$ ).

Houghto-Clean 130. This is an alkaline washing agent. The recommended concentration for the washing bath is $3 \%$. The results of the corrosion tests (Fig.5) show that below this concentration the observed corrosion can be defined as moderate to strong. At the concentration of $3.06 \%$ and above it, the degree of corrosion was 0 , which allows to conclude that the recommended concentration is correct. However, for safety it would be advantageous to prepare slightly more concentrated solutions, for the sake of dilution or fluctuations in the washing apparatus.

Every day in the company's laboratory the washing bath, taken from the washing apparatus is also tested according to the corrosion test. Thus, in the current research the samples from the washing machine were taken and tested. In the real samples the concentrations close to those, recommended for the rinsing bath were too low, and corrosion appeared, while for the samples with the concentrations relevant for the washing process, corrosion was not observed (the results not presented here). These results confirmed our conclusion on the effect of concentration on the anti-corrosion protection properties, obtained from the investigations of the model solutions.

\section{Investigation of Cutting fluids}

The selected cutting fluids were investigated at the concentrations recommended by the producer and at the concentrations below and above these values (Table 1). The results for Hocut 2360 are presented in Fig. 6. It can 


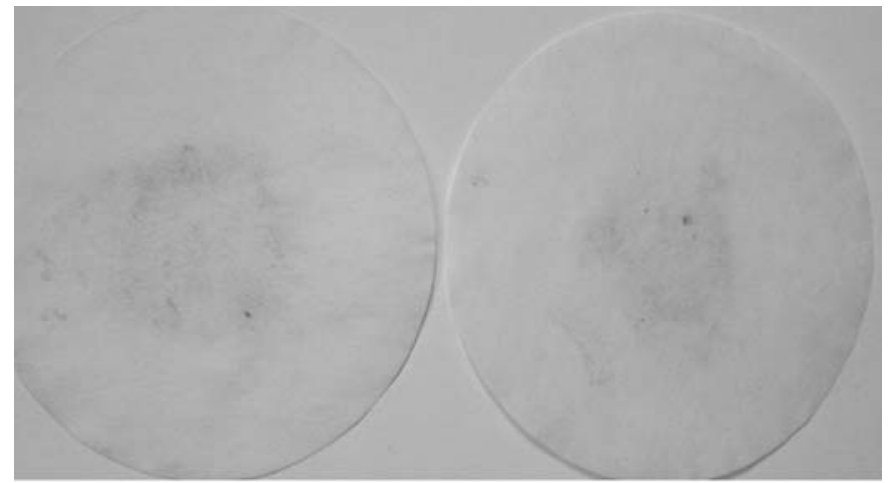

$2 \%, \mathrm{pH} 9$, corrosion degree: 1

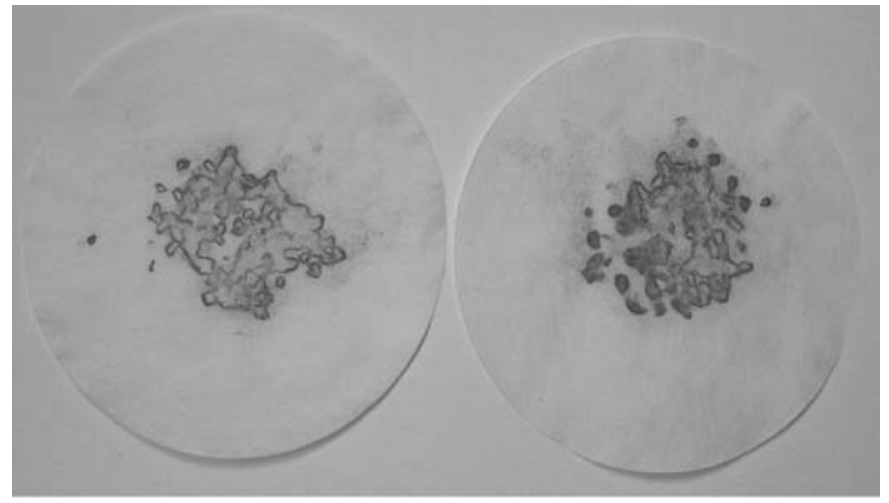

1\%, $\mathrm{pH} 8$, corrosion degree: 5

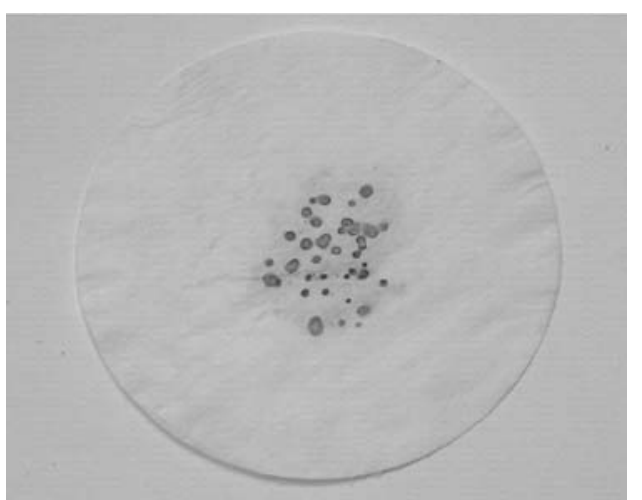

$1.2 \%, \mathrm{pH} 9$, corrosion degree: 3

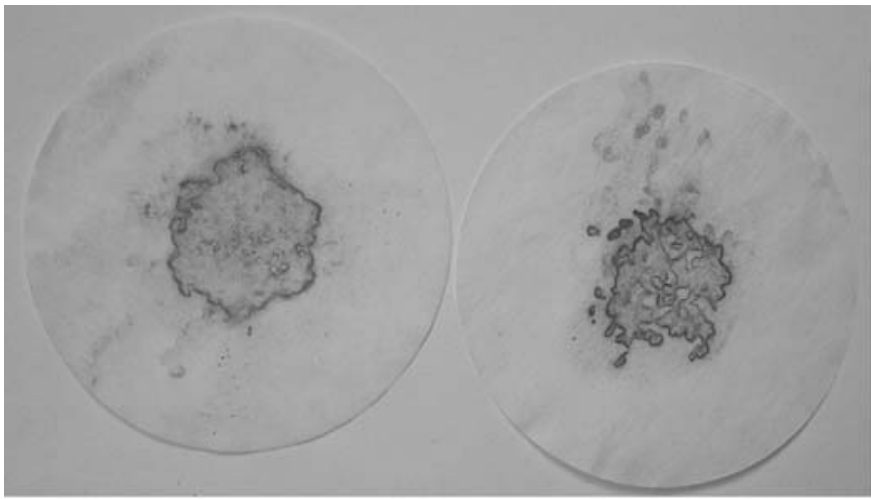

$0.8 \%, \mathrm{pH} 8$, corrosion degree: 5

Figure 3. The view of paper disks after the corrosion test for the Houghto-Clea MT solutions

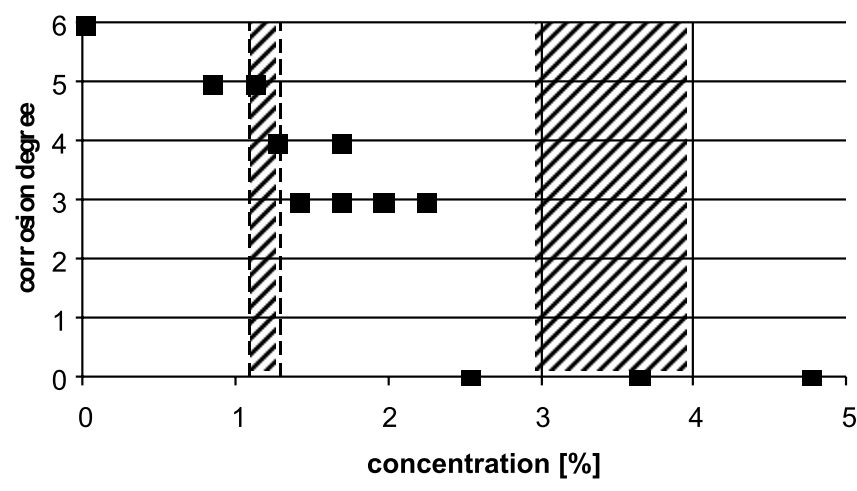

Figure 4. The dependence of the Corrosion Degree on the Renoclean Brilant MS 216 concentration in the tested solutions

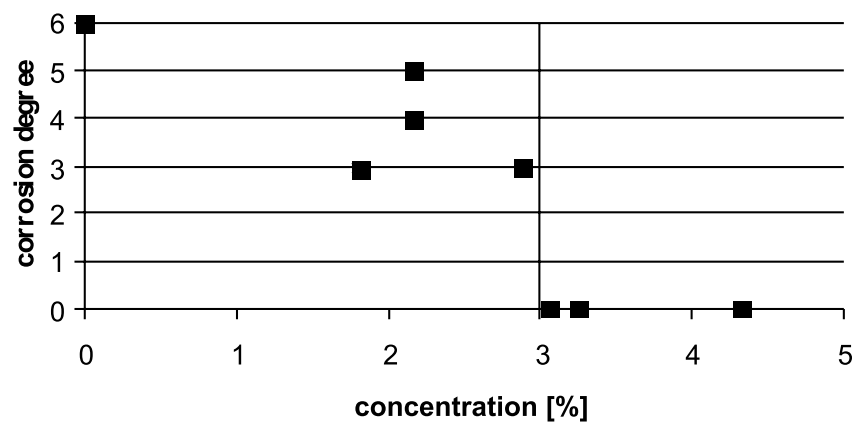

Figure 5. The dependence of the Corrosion Degree on the Houghto-Clean 130 concentration in the tested solutions

be noticed that within the recommended range of concentration the trace corrosion has appeared (the corrosion degree 1 at the concentration of $3.64 \%$ ). Only above this concentration corrosion was not observed. Thus, it can be suggested that the highest value of the concentration range is sufficient for the protection against corrosion. At the concentration above $5 \%$ corrosion was not observed.

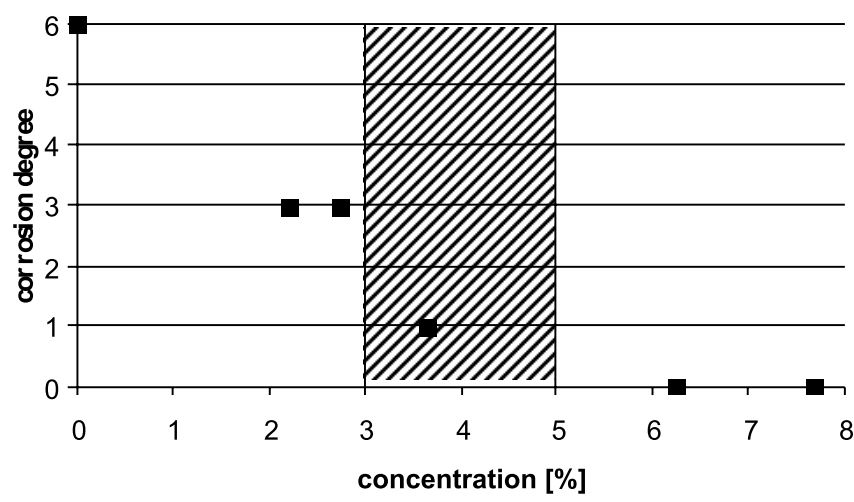

Figure 6. The dependence of the Corrosion Degree on the Hocut 2360 concentration in the tested solutions

In the case of two other cutting fluids, the Hocut B50S and the Curtagil M17, a wide range of concentrations has been tested (Table 1) and no sample demonstrated traces of corrosion, even at the lowest concentrations. Thus, it can be concluded that these two fluids have very good anticorrosion properties, and corrosion will not occur at any concentration of their solutions, recommended by the producer.

\section{CONCLUSIONS}

The working fluids used during the processing of the metal elements should protect them against corrosion. On the basis of the obtained results it has been stated that the lower the fluid concentration is, the stronger corrosion is 
developed. The concentration recommended by the producer is in the case of cutting fluids properly chosen. However, it can be suggested that the HoCut 2360 can be replaced by the HoCut B50S, because the second one is more efficient in corrosion protection at lower concentrations (it can be used even at $1.95 \%$ ). Thus, lower costs due to lower concentration are advantageous.

For washing fluids two regions are distinguished, lower concentration for the rinsing baths and higher concentrations for the washing process. On the basis of the presented results one can conclude definitely that the concentration recommended for rinsing is too low for the protection against corrosion. In many samples the extended corrosion has developed. One may suggest increasing the fluid concentration for this process or supplementing the rinsing solution with the extra dose of an anticorrosion agent. Otherwise, the elements with the developed corrosion have to be treated as the waste product.

\section{ACKNOWLEDGEMENTS}

The authors greatly appreciate all the support given by Houghton Poland Ltd.

\section{LITERATURE CITED}

(1) Zubielewicz M., Gnot W.: Anticorrosion coats of the new generation, Anticorrosion protection, 2005, 4, 98.

(2) Bonora P. L., Lekka M., Creazzi L.: Nanotechnology of coating, Anticorrosion protection, 2006, 4, 130.

(3) Zubielewicz M.: Research trend and development of protection coats, Anticorrosion protection, 2006, 4, 95.

(4) Dąbrowski J., Firkowski A., Gierzyńska-Dolna M.: Cutting fluids in machining, WNT, 1988.

(5) Michel A., Kuhlschmierstoffe für Hochleistungsfertigungsverfaren, Tribologie und Schmierungstechnik, 1998, $3,18$.

(6) PN-92/M-55789 - Research of corrosion effect of the technological liquids on iron alloys. 